\title{
Two Modulatory Inputs Exert Reciprocal Reinforcing Effects on Synaptic Input of Premotor Interneurons for Withdrawal in Terrestrial Snails
}

\author{
Olga A. Maksimova, Natalia I. Bravarenko, and Pavel M. Balaban ${ }^{1}$ \\ Laboratory of Cellular Neurobiology of Learning \\ Institute of Higher Nervous Activity and Neurophysiology \\ Moscow 117865, Russia
}

Abstract

A cluster of serotonergic cells in the rostral part of pedal ganglia of the terrestrial snail Helix lucorum was shown previously to participate in modulation of withdrawal behavior, and to be necessary for elaboration of aversive withdrawal conditioning in intact snails. In the present experiments local extracellular stimulation of the serotonergic cells elicited a pairing-specific increase (difference between paired and explicitly unpaired sessions was significant, $P<0.01$ ) of synaptic responses in the premotor interneurons involved in withdrawal to paired nerve stimulation. Intracellular stimulation of only one Pd4 cell from the pedal group of serotonergic neurons increased $(P<0.05)$ synaptic responses to contingent test nerve stimulation significantly in the same premotor interneurons for $2-3 \mathrm{hr}$.

Mesocerebral cells are known to participate in male sexual behavior, and their extracellular stimulation was shown previously to suppress the amplitude of synaptic responses in withdrawal interneurons. Local extracellular stimulation of the mesocerebral cells elicited a pairing-specific decrease $(P<0.01)$ of synaptic responses to contingent test nerve stimulation in the premotor interneurons involved in withdrawal for 2-3 hr. Paired application of met-enkephaline $\left(10^{-6} \mathrm{M}\right.$, some mesocerebral cells are

${ }^{1}$ Corresponding author. enkephaline-like immunoreactive) also selectively decreased synaptic responses to contingent nerve stimulation in the premotor interneurons for hours. Thus, two modulatory inputs exert pairing-specific effects that influence the same synaptic connection in opposite directions, which may underlie the long-term up- and down-regulation of behavioral responses.

\section{Introduction}

A group of serotonin-containing cells, which modulate the snail withdrawal behavior and activity of neurons underlying it, was described in terrestrial mollusk Helix previously (Zakharov et al. 1995). Firing in these neurons did not elicit any forms of behavior, but changed the behavioral responses evoked by noxious stimuli: This conforms to a definition of modulatory cells. Extracellular stimulation of these serotonergic cells or serotonin application led to short-term facilitation of synaptic and spike responses in the premotor withdrawal interneurons (putative command neurons for withdrawal) induced by noxious stimuli (Zakharov and Balaban 1991; Zakharov et al. 1995).

Male copulatory behavior of the gastropod snails is controlled by a neuronal network that consists of various types of peptidergic neurons. Among them is a cluster of neurons in the anterior lobe of the cerebral ganglia (mesocerebrum, MsCer) innervating the penis complex and various central neurons affecting the mating behavior (Chase 1986). In Helix this functional cluster was shown to contain several peptides presumably involved in the mating behavior: FMRFamide (Elekes and Nassel 1990; Marchand et al. 1991), APGWamide and other peptides processed from the

LEARNING \& MEMORY 6:168-176 @ 1999 by Cold Spring Harbor Laboratory Press ISSN1072-0502/99 \$5.00

$$
\begin{array}{lllllllllllllll}
L & E & A & R & N & I & N & G & \underset{168}{\boldsymbol{Z}} & M & E & M & O & R & Y
\end{array}
$$


APGWamide propeptide (Croll et al. 1991; Griffond et al. 1992; Smit et al. 1992) (Lymnaea, Helix), enkephalin-like peptides (Marchand et al. 1991; Elekes et al. 1993). Extracellular activation of mesocerebral neurons involved in male sexual behavior suppressed the amplitude of synaptic responses for several minutes in the premotor withdrawal interneurons (Balaban and Chase 1990).

We investigated modulatory properties of serotonergic neurons and of peptidergic mesocerebral cells exerting reciprocal short-term effects on amplitude of synaptic input in withdrawal interneurons. In this investigation synaptic inputs to the premotor interneurons for withdrawal were paired or explicitly nonpaired with activation of modulatory cells. It appeared that extracellular activation of a group of serotonergic cells or mesocerebral cells can serve as a reinforcement, changing for hours the effectivity of synaptic input to withdrawal interneurons in opposite directions. Activity in a single serotonergic cell can also mediate the reinforcement in the withdrawal network of the terrestrial snail.

\section{Materials and Methods}

\section{ANIMALS AND PREPARATIONS}

Experiments were carried out in adult snails Helix lucorum L. All animals were kept in terraria. Isolated central nervous system (CNS) or CNS with attached sexual organs was used. Details are given elsewhere (Maximova and Balaban 1984; Balaban et al. 1987; Balaban and Maksimova 1993). A slow saline flow ( $1 \mathrm{ml} / \mathrm{min}$, chamber volume $2 \mathrm{ml}$ ) was used, unless specified otherwise. Fast washout was used in some experiments.

\section{ELECTROPHYSIOLOGY}

Conventional microelectrode techniques were used for simultaneous intracellular recording from up to four identified neurons. Extracellular stimulation of cellular somata (tetanization, Fig. 1A) was accomplished by using glass suction electrodes having inner diameters of 100-250 $\mu \mathrm{m}$. Parameters of extracellular tetanization were: frequency $5 \mathrm{~Hz}$, pulse duration $3 \mathrm{msec}$ and train duration $10 \mathrm{sec}$. The effective voltage was variable $(0.5-3 \mathrm{~V})$, and was chosen individually in every experiment. The criterion for the threshold level of stimulation was the change in spontaneous or evoked activity in
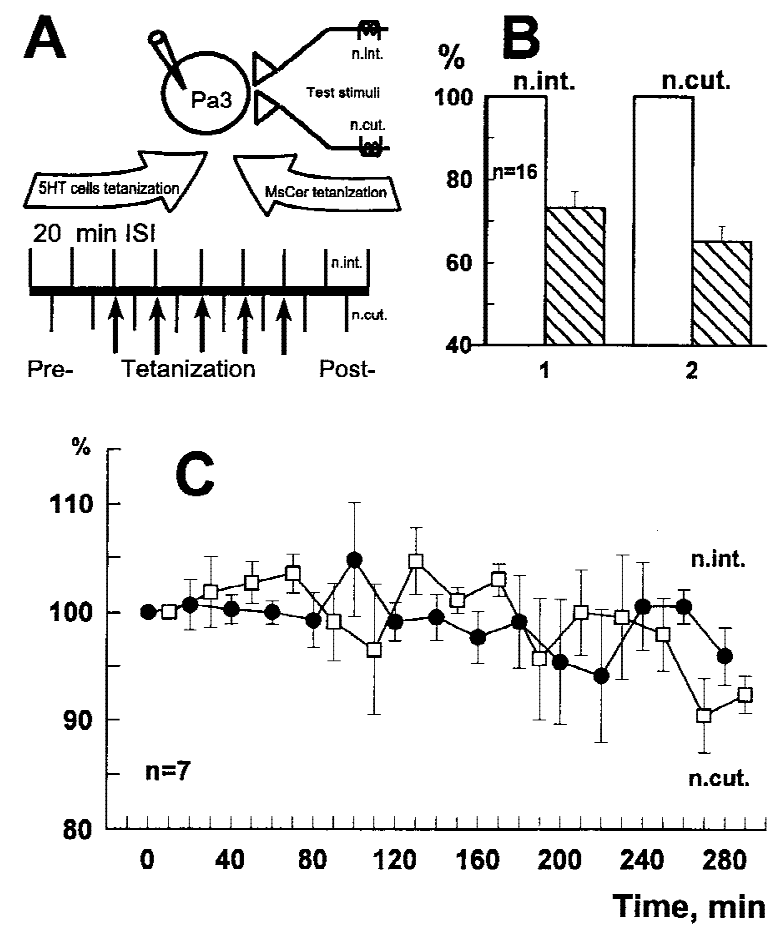

Figure 1: Properties of synaptic input to the premotor parietal interneurons. (A) Schematic representation of protocol of the experiment; $(B)$ averaged amplitude of responses to test stimuli via intestinal nerve (n.int.) or second cutaneous nerve (n.cut.) before and 2 min after extracellular stimulation of mesocerebrum; open bars represent the EPSP before mesocerebral cell stimulation; hatched bars represent the EPSP after stimulation. (C) Dynamics of habituation to the independent test stimuli to two nerves without the contingent stimulation.

the giant parietal cells, but the intensity never exceeded $3 \mathrm{~V}$. In several experiments, the effectiveness of extracellular tetanization was investigated by recording intracellularly from neurons under and near the suction electrode. With the electrodes used, this voltage evoked spikes only in cells under and in the vicinity of the extracellular electrode tip, at a distance of $\sim 100 \mu$ in diameter. Average size of neurons in stimulated part of parietal ganglia is 50-60 $\mu \mathrm{m}$ (identifiable neurons Pd1-4 are bigger, up to $150 \mu \mathrm{m}$ ), leading us to estimate that we stimulated $\sim 30$ neurons. In the MsCer the dimensions of neurons in adult snails were similar. In experiments with MsCer stimulation the sexual organs were preserved on the preparation, and the threshold was estimated on the basis of appearance of movements of the penis.

Test electrical stimuli were applied via polyethylene suction electrodes to the intestinal nerve

$$
\begin{array}{lllllllllllllll}
L & E & A & R & N & I & N & G & \begin{array}{c}
\boldsymbol{Z} \\
\mathbf{1 6 9}
\end{array} & M & E & M & O & R & Y
\end{array}
$$


and/or second cutaneous nerve which do not contain processes of the recorded cells. Stimulus intensity (0.5-3 V, duration $3 \mathrm{msec}$ ) was adjusted in each experiment to evoke the complex EPSPs of 4-10 $\mathrm{mV}$ amplitude.

The experimental protocol included pretesting, paired or explicitly nonpaired procedures, and post-testing (Fig. 1A). Long (5 or $20 \mathrm{~min}$ ) intervals between test stimuli were used to diminish the low-frequency depression typical for the studied connections depending on interstimulus interval (Bravarenko et al. 1995). Intracellular tetanization consisted of 10 bursts of 30-msec depolarizing pulses. Burst duration and interburst intervals were $10 \mathrm{sec}$. Pulse frequency in each burst was $16 \mathrm{~Hz}$, pulse duration $30 \mathrm{msec}$. Current strength (5-15 nA) was suprathreshold. Spikes were evoked only by some pulses at these frequencies, but the quantity of action potentials elicited in the Pd 4 was $>50$ per $10 \mathrm{sec}$ of one train of tetanization.

Recordings were digitized (DIGIDATA 1200, Axon Instruments, Inc., Foster City, CA) at $1 \mathrm{kHz}$ and fed into an IBM PC compatible computer. Peak excitatory postsynaptic potential (EPSP) amplitudes were measured using Axotape software.

For statistical evaluations, nonparametric Mann-Whitney rank sum test was used. Significantly different corresponds to at least $P<0.05$, if not stated otherwise. Data were normalized to the first EPSP in the experiment. Data are presented as the mean \pm s.E.M.

Some of the experiments were performed in snails with vitally stained serotonergic cells. To obtain selective vital staining of serotonergic cells, snails were injected 2 months previously with a serotonergic cell-selective neurotoxin 5,7-DiHT twice with a 1-day interval $(10 \mathrm{mg} / \mathrm{kg}$ of body weight; details in Balaban et al. 1985). It has been shown previously that 2 months after the injection the synaptic connections and normal levels of 5-HT are restored in serotonergic cells (Gadotti et al. 1986; Vehovzsky et al. 1989), whereas somata of the cells obtain a permanent red-brown staining (Balaban et al. 1985; Vehovzsky et al. 1989). Comparison of pigment labeling by 5,6-DiHT or 5,7-DiHT and immunolabeling techniques established that all the pigment-labeled neurons show 5-HT immunoreactivity in Helix (Hernadi et al. 1989).

A total of 83 neurons were investigated in experiments with contingent stimulation of MsCer or pedal serotonergic cluster

\section{Results}

SYNAPTIC INPUTS TO THE PREMOTOR (COMMAND) NEURONS FOR WITHDRAWAL

To obtain the synaptic responses not affected by antidromic spikes, we alternatively stimulated (1/20 min each with 10-min shift, Fig. 1A) the second cutaneous nerve of pedal ganglion and intestinal nerve originating from visceral ganglion. Stimulation of either nerve elicited complex EPSPs in premotor interneurons that normally habituate very slowly if stimuli are applied once in $20 \mathrm{~min}$ (Fig.1C). During $5 \mathrm{hr}$ of experimentation the EPSP amplitude decreased usually to the $90 \%$ level of the initial amplitude (Fig. 1C). In each experiment we extracellularly stimulated MsCer or serotonergic pedal cells contingently with stimulation of one of the nerves, whereas explicitly unpaired stimulation (10 min apart of extracellular stimulation of the modulatory cells) of another nerve served as a control (Fig. 1A). In a pilot series of experiments it was found that 2 min after the MsCer extracellular stimulation the response to the test stimulation decreased significantly, and this effect was found to be similar for complex EPSPs evoked by test stimulation of both used in experiments nerves (Fig. 1B). The EPSP amplitude to test stimulus returned to initial value $10 \mathrm{~min}$ after the stimulation. A test for such effect was performed in each experiment prior the training session to verify the extracellular electrode position. The preparation was considered to be in good condition if a transient decrease of EPSP (>20\% of the initial value) shortly after the MsCer tetanization was observed. From 36 preparations in 30 cases this criterion was met, and the preparations were included in the final experiments. This decrease demonstrated that in the particular experiment the stimulated cells exert the investigated effect, and the connectives from cerebral to parietal ganglia are not damaged. In experiments with extracellular tetanization of 5HTcontaining cells (performed separately from the experiments with MsCer tetanization) the preparation was qualified as good if a small $(2-4 \mathrm{mV})$ depolarization was observed in parietal giant neurons after the tetanization pulse. From 29 experiments the criterion was met in 21 cases taken for training.

\section{CONTINGENT EXTRACELLULAR STIMULATION OF MESOCEREBRAL CELLS}

In our main series of 30 experiments it was observed that stimulation of either nerve paired

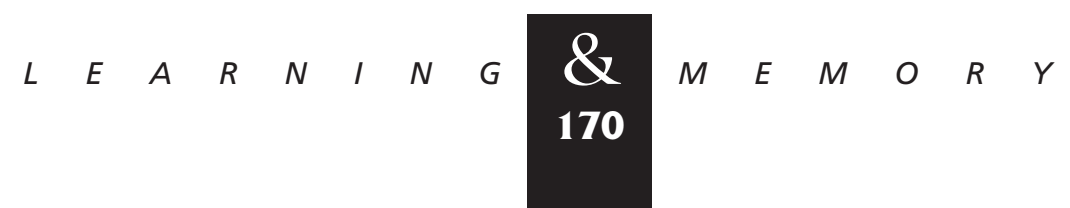



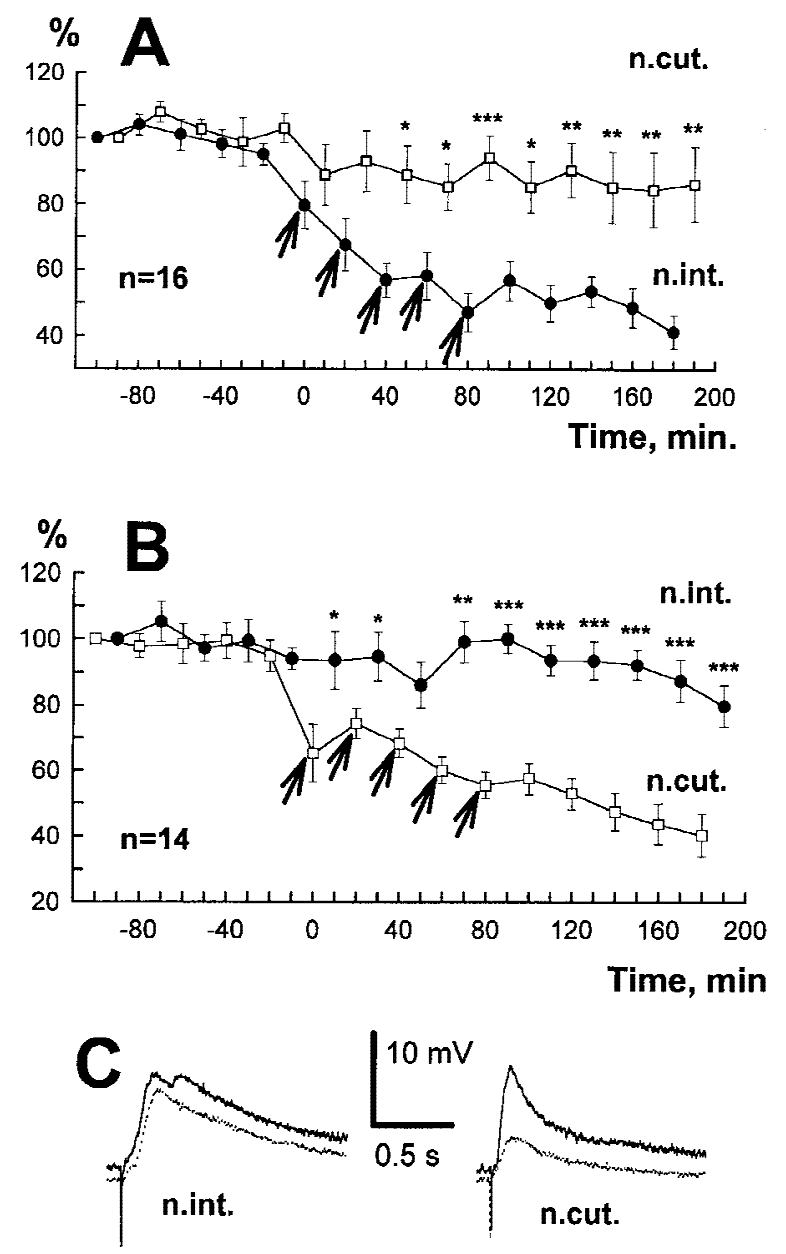

Figure 2: (A) Averaged changes (mean \pm S.E.M.) in amplitude of complex EPSPs evoked in parietal giant neurons by stimulation of intestinal nerve (n.int.) paired and second cutaneous nerve (n.cut) explicitly unpaired with extracellular activation (arrows) of mesocerebral cells. (B) Same protocol of experiment, but n.cut. was paired. Initial response was taken in all experiments as $100 \%$. Arrows mark paired trials. $(C)$ Examples of complex EPSPs in right parietal neuron 2 in response to test stimuli to n.int. (left, unpaired) and n.cut. (right, paired procedure) before and after pairing (solid and dotted lines, respectively); the example is taken from one of experiments averaged in $B$. Stimulus artifact is seen. Here and in Figs. $3-5$ : $\left(^{*}\right) P<0.05 ;\left({ }^{* *}\right) P<0.01 ;(* *)$ $P<0.001$, Mann-Whitney rank sum test.

with the MsCer tetanization significantly $(P<0.01$ after five pairings) decreased amplitude of synaptic response to the paired test input relative to the unpaired one (Fig. 2A,B). Significant difference between the amplitude of responses in inputs contingent with extracellular tetanization of MsCer and noncontingent inputs lasted for 2-3 hr (Fig. 2).
To test whether the inputs (nerves) used for the test stimulation behave differently with contingent extracellular tetanization, we alternated the nerve that was used for contingent stimulation in different experiments. The results obtained showed independence of effect-pairing-specific long-term decrease of synaptic responses to the test stimulation-of the type of test input (Fig. 2A,B). An example of pairing-specific changes in the complex EPSP amplitude elicited by unpaired (left) and paired test stimuli is shown in Figure 2C.

It is well known that cells in MsCer contain several peptides, and some neurons are immunopositive (Marchand et al. 1991; Elekes et al. 1993). We conducted a series of 14 experiments testing whether a contingent bath application of a synthetic met-enkephalin will produce significant difference in responses to contingently and noncontingently stimulated inputs. Met-enkephalin was added in final concentration $10^{-6} \mathrm{M}$ to the saline $1 \mathrm{sec}$ prior the test stimulation ( $1 \mathrm{sec}$ is the estimated time it takes to reach the CNS in our chamber), and was washed out in the middle of the 10-min interval between consecutive test stimuli. It was found in 14 preparations that the bath application of met-enkephalin can serve as a contingent stimulus and also elicits a significant $(P<0.05)$ pairing-specific changes in complex EPSP amplitude (Fig. 3) quite similar to the changes evoked by contingent MsCer tetanization (Fig. 2).

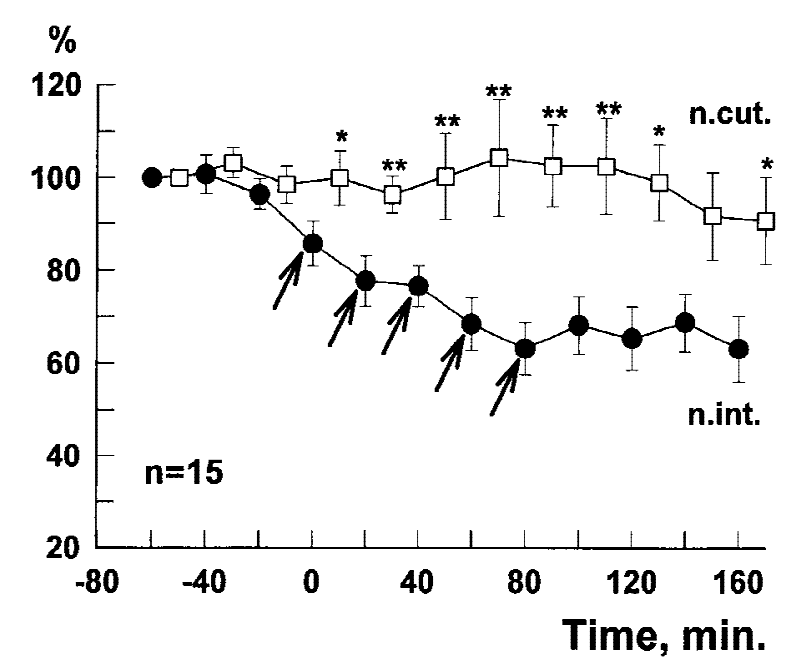

Figure 3: Averaged changes (mean \pm S.E.M.) in amplitude of complex EPSPs evoked in parietal giant neurons by paired stimulation of intestinal nerve (n.int.) with bath application of metenkephalin. Stimulation of second cutaneous nerve (n.cut.) was explicitly unpaired with application of met-enkephalin.

$$
\begin{array}{lllllllllllllll}
L & E & A & R & N & I & N & G & \mathbf{Q} & M & E & M & O & R & Y \\
\mathbf{1 7 1} & & & & & &
\end{array}
$$




\section{Maksimova et al.}

CONTINGENT EXTRACELLULAR ACTIVATION

OF THE PEDAL SEROTONERGIC CELLS CAN SERVE AS A REINFORCEMENT

Results published previously showed the necessity of serotonergic cells for long-term behavioral sensitization and elaboration of associative conditioning (including context conditioning) using noxious stimuli eliciting withdrawal as a reinforcement (Zakharov and Balaban 1991; Balaban and Bravarenko 1993; Zakharov et al. 1995). The presence of serotonergic fibers surrounding the soma of withdrawal premotor interneurons with a dense network without synaptic specializations (suggesting modulatory influence) was clearly demonstrated immunochemically (Vehovzsky et al. 1993). Therefore, we tested the assumption that serotonergic cells can mediate the reinforcement. We performed experiments in which the EPSPs induced by nerve stimulation in the withdrawal interneurons were paired with local extracellular stimulation (suction electrode 100-250 in diam.; diameter of neural somata $40-60 \mu \mathrm{m}$ ) of serotonergic neurons in the rostral part of the ipsilateral pedal ganglion. It should be noted that in 12 pilot experiments no effects were found when we stimulated serotonergic cells located on the border of visceral and right parietal ganglia, similar to earlier results (Zakharov et al. 1995).

In 21 experiments with pairing we used a procedure similar to used in experiments with MsCer (Fig. 1A). After the pretetanization testing five test stimuli to the intestinal nerve were paired with the pulse of extracellular stimulation of serotonergic cells (10-sec duration, 3-msec pulses with $5 \mathrm{~Hz}$ frequency). A post-tetanization testing followed this. As a control, in the same experiment an explicitly unpaired test stimulus to another nerve was used (Fig. 1A). A 20-min interval between test stimuli was selected to avoid habituation and overlapping of effects in the explicitly unpaired procedure. The averaged data from 21 experiments (Fig. 4) showed a significant difference $(P<0.01$, MannWhitney rank sum test) between the amplitude of EPSPs to test stimuli in premotor withdrawal neurons of paired and unpaired groups starting on the fortieth minute after the beginning of reinforcing stimulation. The results suggested that pedal serotonergic neurons were capable of contingently increasing the amplitude of the withdrawal neuron responses to nerve stimulation. At a behavioral level this increase would result in increase of withdrawal responses similar to that observed during

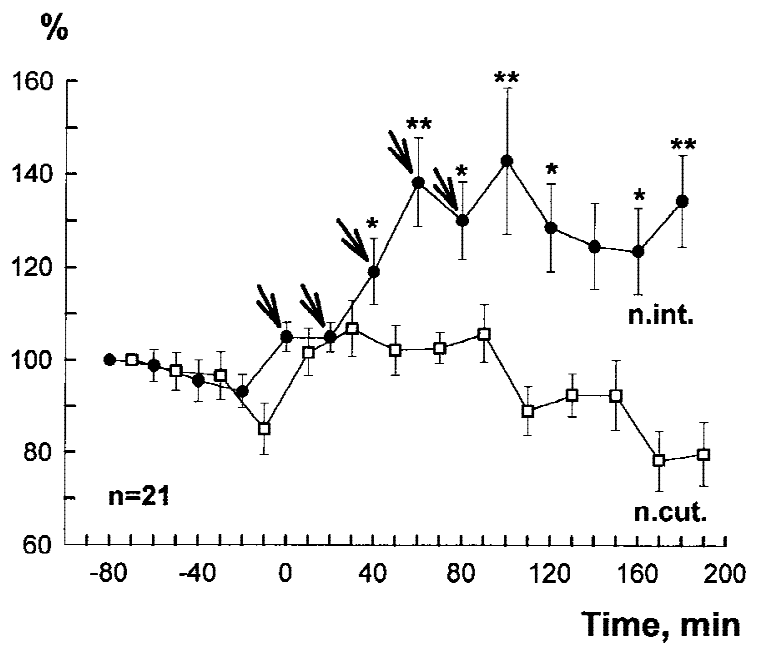

Figure 4: Averaged changes (mean \pm S.E.M.) in amplitude of complex EPSPs evoked in parietal giant neurons by paired stimulation of intestinal nerve (n.int.) and stimulation of second cutaneous nerve (n.cut.) explicitly unpaired with extracellular activation (arrows) of serotonergic pedal cells. Initial response was taken in all experiments as $100 \%$. $\left(^{*}\right) P<0.05$; $\left(^{* *}\right) P<0.01$, MannWhitney rank sum test.

context conditioning (Balaban and Bravarenko 1993) and aversive learning (Balaban et al. 1987).

\section{ONE MODULATORY CELL CAN MEDIATE THE REINFORCEMENT}

The experiments using extracellular stimulation described above cannot identify individual neurons involved in neuromodulation or provide important information about cellular mechanisms. Therefore, we used intracellular stimulation of individual cells in the rostral region of the pedal ganglia. The training procedure was changed to shorten the training session. Test stimuli were delivered with 5-min intervals before and after the pairing session. Increase of test stimulation frequency normally increases the habituation rate (Balaban and Zakharov 1992). At a frequency of one per $5 \mathrm{~min}$, the response in parietal giant cells to test stimulation via the intestinal nerve usually habituates to $65 \%-75 \%$ of the initial value (Bravarenko et al. 1995; Malyshev et al. 1997). A pairing session (Fig. 5A) consisted of five test stimuli with 2-min intervals, and five reinforcing intracellular trains, which were given simultaneously with the test stimuli (paired procedure) or between test stimuli in a pairing session (explicitly unpaired group; Fig. 5A). The EPSP amplitude was not ana-

$$
\begin{array}{lllllllllllllll}
L & E & A & R & N & I & N & G & \underset{\mathbf{1 7 2}}{\boldsymbol{Z}} & M & E & M & O & R & Y
\end{array}
$$


A

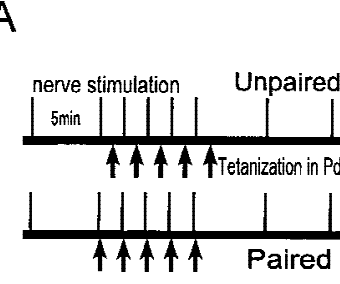

B

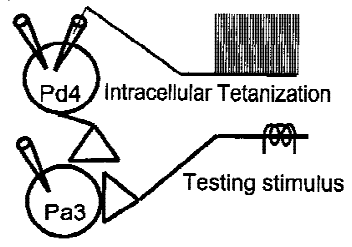

C

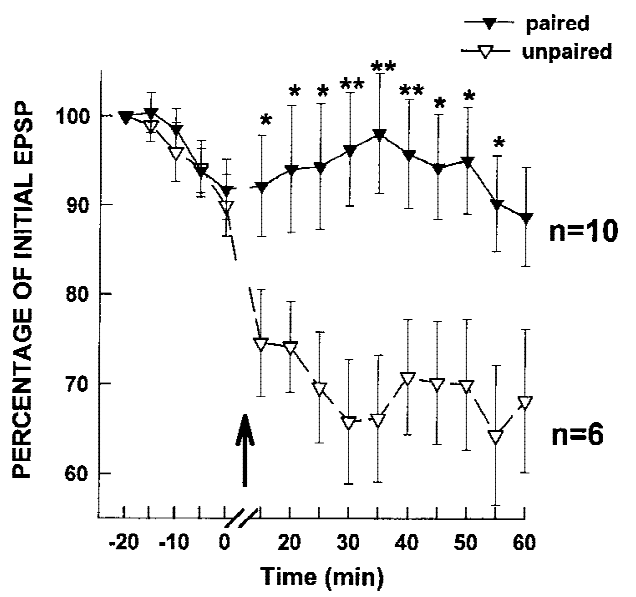

Figure 5: Changes in amplitude of complex EPSPs evoked in parietal giant neurons by stimulation of intestinal nerve (n.int.) paired and explicitly unpaired with intracellular activation of cell Pd4. (A) Diagram of experiment; $(B)$ scheme of recording and experimental setup; $(C)$ averaged results (mean \pm S.E.M.) $(*) P<0.05$; $(* *) P<0.01$, Mann-Whitney rank sum test. $(\boldsymbol{\nabla})$ Paired; $(\nabla)$ unpaired. Initial response was taken in all experiments as $100 \%$. The training session is marked by breaks in axes and an arrow.

lyzed during the testing session (the gap on Fig. 5C) because the artifacts of tetanization in the paired procedure masked the form of the EPSPs. The reinforcing intracellular tetanization consisted of one 10-sec duration train of $25-33$ msec depolarizing pulses at $15-20 \mathrm{~Hz}$. The current strength (5-10 nA) was suprathreshold. Giant parietal withdrawal interneurones (mainly LPa3 and RPa3) and one of the pedal serotonergic cells were penetrated with one or two glass microelectrodes. The second electrode in the pedal cell was used for intracellular tetanization and injection of biocytin (Fig. 5B). In most experiments, the training procedure was repeated twice: one paired and one unpaired session. In total 27 experiments were performed. In 12 of them the snails with serotonergic cells previously vitally labeled by 5,7-dihydroxytriptamine were used (Balaban et al. 1985). In these experiments we impaled mostly the serotonergic cells that are not readily identified by their size and location. Brown pigmentation in 5,7-DiHTlabeled cells allowed us to be sure that a serotonergic cell was impaled. In most experiments, pedal cells were filled with biocytin after the experiment to verify the morphology of the recorded cell.

To our surprise, we never observed any modulatory or pairing-specific effects in the experiments, in which we tetanized unidentified small serotonergic pedal neurons or serotonergic Pd2 cells. The difference between responses in paired and unpaired situations was close to zero in 16 experiments, and never exceeded the standard error of the mean on averaging. Only when intracellular tetanization of Pd4 cells was used as a reinforcement, did we observe an increase in EPSP amplitude during the paired procedure ( $n=10$; Fig. 5C). Significant changes were observed immediately after the last tetanization $(P<0.05$, MannWhitney rank sum test, corresponding values were compared in experiments with paired and unpaired procedures). Thirty minutes after the pairing session the difference was even more significant $(P<0.01)$, and up to the fiftieth minute the difference between paired and explicitly unpaired situations was significant (Fig. 5C). In general, results were similar to those obtained in the experiments with extracellular stimulation of serotonergic neurons (Fig. 4). Thus, intracellular stimulation of only one Pd4 cell can mediate a pairing-specific increase of the amplitudes of the EPSPs in the parietal giant neurons controlling withdrawal behavior.

\section{Discussion}

\section{BEHAVIORAL SIGNIFICANCE OF SYNAPTIC INPUT CHANGES IN PARIETAL PREMOTOR INTERNEURONS}

Two symmetrically located giant parietal neurons shown to be involved in withdrawal (Balaban 1979 , 1983) were chosen as target postsynaptic cells for the experiments. The properties of giant parietal cells conform to the definition of command neurons for withdrawal, and it was shown that increases in spike discharge to the external stimuli in these cells corresponds to increases in the behavioral withdrawal response (Balaban 1983; Balaban et al. 1987; Balaban and Zakharov 1992). Sensory input to these cells is polymodal (Balaban 1983). Habituation and sensitization of Helix withdrawal responses corresponds to the changes in amplitude of complex EPSPs and quantity of action potentials in a discharge in these cells in response

$$
\begin{array}{lllllllllllllll} 
& E & A & R & N & I & N & G & \boldsymbol{Q} \\
\mathbf{1 7 3} & M & E & M & O & R & Y
\end{array}
$$




\section{Maksimova et al.}

to noxious stimuli (Balaban 1991). It suggests that plastic changes underlying the behavioral changes occur at least partially at the level of synaptic input to these premotor interneurons, pre- and postsynaptic sites involved (Bravarenko et al. 1995; Malyshev et al. 1997). Therefore, the main idea of the present investigation was to find out whether paired with the test stimuli stimulation of the two brain structures involved in different behaviors and reciprocally influencing the synaptic input of the cells in question can be different from an unpaired stimulation.

\section{ROLE OF SEROTONERGIC NEURONS \\ IN WITHDRAWAL BEHAVIOR}

Numerous studies in several gastropod species have indicated that the neurotransmitter serotonin has a modulatory role in feeding behavior (Gelperin 1981; Kupfermann and Weiss 1981). Serotonin also plays an essential role in modulation of withdrawal reactions in mollusks (Kandel and Schwartz 1982; Balaban et al. 1987; Glanzman et al. 1989).

It was shown clearly in cultured Aplysia neurons that temporal pairing of presynaptic activity and serotonin application enhances facilitation at sensory-motor neuron synapses (Eliot et al. 1994; Bao et al. 1998). Intracellular stimulation of identified cerebral Aplysia neurons CB1 produced facilitation of the EPSPs from siphon sensory neurons to motor neurons suggesting participation of these individual serotonergic cells in mediation of presynaptic facilitation (Mackey et al. 1989). Activation of an identified modulatory cell (slow oscillator) in Lymnaea stagnalis elicited associative enhancement of fictive feeding response (Kemenes et al. 1997). An identified neuromodulatory interneuron, which serves the reinforcing function during associative learning was described in the honeybee (Hammer and Menzel 1995). In our experiments, a contingent activation of pedal serotonergic cells with one of two test synaptic inputs resulted in selective long-term increase of reinforced input in the premotor withdrawal interneurons (Fig. 4). Increase of synaptic input to external stimuli in these cells is manifested at the behavioral level as an increase in withdrawal responses amplitude. Participation of serotonergic cells in mediating the reinforcement in such a model situation conformed to results published previously (Balaban et al. 1987; Balaban 1993; Balaban and Bravarenko 1993).
Contingent activation of only one pedal serotonergic cell produced a long-term facilitation of the synaptic inputs to the withdrawal interneurons (Fig. 5), which is similar to the facilitation induced in Helix by exogenous serotonin (Balaban et al. 1986, 1991; Zakharov et al. 1995). It is also similar to the facilitation elicited by contingent extracellular activation of the entire group of pedal serotonergic neurons (Fig. 4). These results suggest a neuromodulatory role for the single pedal serotonergic neuron Pd4, which can mediate the reinforcement, and confirm participation of serotonergic cells in aversive conditioning.

MESOCEREBRAL CELLS AND WITHDRAWAL BEHAVIOR

Previous work has identified a part of the brain in Helix sp. that appears to control at least some aspects of sexual behavior (Chase 1986). Electrical stimulation of the right MsCer with an extracellular suction electrode caused contraction of the penis sheath and the "love dart" sac. Intracellular stimulation of individual mesocerebral neurons caused contractions of reproductive organs. These effects are mediated by axons that travel directly from the MsCer to the subesophageal ganglia (Chase 1986). During mating, snails exhibit a marked suppression of the defensive withdrawal responses triggered normally by tactile contacts. In semi-intact preparations, extracellular stimulation of mesocerebral cells elicited a decrease in the number of action potentials evoked in giant parietal interneurons and a corresponding decrease in the amplitude of pneumostome closure (part of withdrawal behavior) (Balaban and Chase 1990). Described effects provide a partial explanation for the suppression of withdrawal responses during mating between snails. In the present paper we showed that MsCer stimulation can mediate reinforcement in situation when it is stimulated contingently with synaptic input to the withdrawal interneurons (Fig. 2). Contingent application of met-enkephalin $\left(10^{-6} \mathrm{M}\right.$; some mesocerebral cells are enkephalin-like immunoreactive), shown to decrease the amplitude of synaptic responses, also selectively decreased synaptic responses to conditioned nerve stimulation in the premotor interneurons for hours (Fig. 3).

Summarizing the obtained results, it is essential to note that in all experiments the mesocerebral stimulation caused a decrease of amplitude of synaptic input to the premotor interneurons, whereas stimulation of parietal giant cells led to opposite effect: increase of amplitude of synaptic

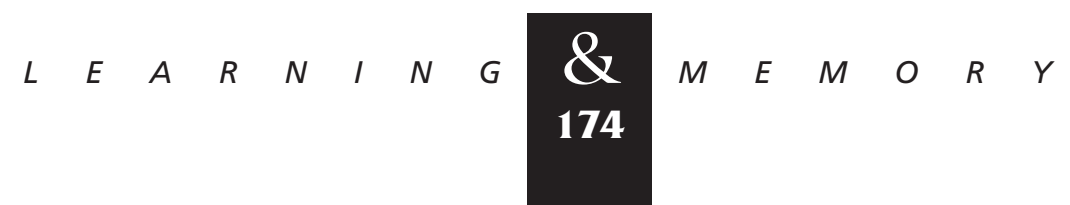


input to the same premotor interneurons. Thus, two modulatory inputs exert pairing-specific effects that influence the same synaptic connection in opposite directions, what may underlie the longterm up- and down-regulation of behavioral responses.

\section{Acknowledgments}

We are grateful to I. Zakharov for helpful discussion and criticism. The work was partly supported by grants from Russian Foundation for Basic Research, NATO grant HTECH.LG973297, and Howard Hughes Medical Institute grant no. 75195-544301.

The publication costs of this article were defrayed in part by payment of page charges. This article must therefore be hereby marked "advertisement" in accordance with 18 USC section 1734 solely to indicate this fact.

\section{References}

Balaban, P.M. 1979. A system of command neurons in snail's escape behavior. Acta Neurobiol. Exper. 39: 97-107.

1983. Postsynaptic mechanism of withdrawal reflex sensitization in the snail. J. Neurobiol. 14: 365-375.

1991. Command neurons, command function and decision making. In Simple nervous systems (ed. D.A. Sakharov and W. Winlow ), pp. 360-374. Manchester University Press, Manchester, NY.

Behavioral neurobiology of learning in terrestrial snails. Prog. Neurobiol. 41: 1-19.

Balaban, P. and N. Bravarenko. 1993. Long-term sensitization and environmental conditioning in terrestrial snails. Exp. Brain Res. 96: 487-493.

Balaban, P.M. and R. Chase. 1990. Stimulation of mesocerebrum in Helix aspersa inhibits the neural network underlying avoidance behavior. J. Comp. Physiol. A 166: $421-427$.

Balaban, P.M. and O.A. Maksimova. 1993. Positive and negative brain zones in the snail. Eur. J. Neurosci. 5: 768-774.

Balaban, P.M. and I.S. Zakharov. 1992. Learning and development: Common basis of two phenomena. (in Russian) Nauka, Moscow, Russia.

Balaban, P.M., I.S. Zakharov, and V.N Matz. 1985. Selective vital staining of serotonergic cells by 5,7-dihydroxytryptamine. Dokl. Akad. Nauk SSSR 283: 735-738.

Balaban, P.M, I.S. Zakharov, O.A. Maksimova, and M.V. Chistyakova. 1986. Serotonin significance in formation of defensive conditioned reflex to food in snail.

Neurophysiologia 18: 291-298.

Balaban, P.M., A. Vehovzsky, O.A. Maximova, and I.S
Zakharov. 1987. Effect of 5,7-dihydroxytryptamine on the food-aversive conditioning in the snail Helix lucorum $L$. Brain Res. 404: 201-210.

Balaban, P., I. Zakharov, and M. Chistyakova. 1991. Integrative role of serotonin in withdrawal and feeding behavior in the terrestrial snail. In Signal molecules and behavior (ed. W.Winlow, O.S. Vinogradova, and D.A. Sakharov), pp. 77-100. Manchester University Press, Manchester, NY.

Bao, J.X., E.R. Kandel, and R.D. Hawkins. 1998. Involvement of presynaptic and postsynaptic mechanisms in a cellular analog of classical conditioning at Aplysia sensory-motor neuron synapses in isolated cell culture. J. Neurosci. 18: $458-456$.

Bravarenko, N.I., P.V Gusev, P.M Balaban, and L.L Voronin. 1995. Postsynaptic induction of long-term synaptic facilitation in snail central neurons. NeuroReport 6: 1182-1186.

Chase, R.J. 1986. Brain cells that command sexual behavior in the snail Helix aspersa. J. Neurobiol. 17: 669-679.

Croll, R.P., J. Van Minnen, K.S. Kits, and A.B. Smit. 1991. APGWamide: Molecular, histological and physiological examination of a novel neuropeptide involved with reproduction in the snail, Lymnaea stagnalis. J. Mollusc. Neurobiol. 248-254.

Elekes, K. and D.R. Nassel. 1990. Distribution of FMRF-amide-like immunoreactive neurons in the central nervous system of the snail Helix pomatia. Cell. Tissue Res. 262: $177-190$.

Elekes, K., G.B. Stefano, and D.O. Carpenter. 1993. Enkephalin-like immunoreactive neurons in the central nervous system of gastropods (Helix pomatia, Lymnaea stagnalis, Aplysia californica): A comparative immunocytochemical study. Cell Tissue Res. 272: 329-341.

Eliot, L.S., R.D. Hawkins, E.R. Kandel, and S. Schacher. 1994. Pairing-specific, activity-dependent presynaptic facilitation at Aplysia sensory-motor neuron synapses in isolated cell culture. J. Neurosci. 14: 368-383.

Gadotti, D., L.G. Bauce, K. Lukowiak, and A.G.M. Bulloch. 1986. Transient depletion of serotonin in the nervous system of Helisoma. J. Neurobiol. 17: 431-447.

Gelperin, A. 1981. Synaptic modulation by identified serotonin neurons. In Serotonin neurotransmission and behavior (ed. B.L. Jacobs and A. Gelperin.), pp. 288-307. M.I.T. Press, Cambridge, MA.

Glanzman, D.L., S.L. Mackey, R.D. Hawkins, A.M. Dyke, P.E. Lloyd, and E.R. Kandel. 1989. Depletion of serotonin in the nervous system of Aplysia reduces the behavioral enhancement of gill withdrawal as well as the heterosynaptic facilitation produced by tail shock. J. Neurosci. 9: 4200-4013.

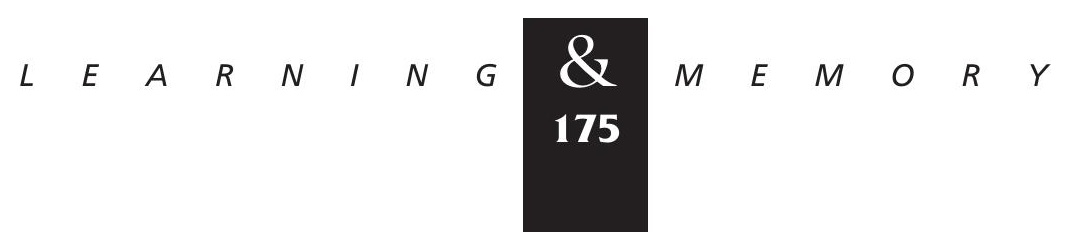




\section{Maksimova et al.}

Griffond, B., J. Van Minnen, and C. Colard. 1992. Distribution of APGWa-immunoreactive substances in the central nervous system and reproductive apparatus of Helix aspersa. Zool. Sci. 9: 533-539.

Hammer, M. and R. Menzel. 1995. Learning and memory in the honeybee. J. Neurosci. 15: 1617-1630.

Hernadi, L., K. Elekes, and K.S. Rozsa. 1989. Distribution of serotonin-containing neurons in the central nervous system of the snail Helix pomatia.Comparison of immunocytochemical and 5,6-dihydroxytryptamine labelling. Cell Tissue Res. 257: 313-323.

Kandel, E.R. and J.H. Schwartz. 1982. Molecular biology of learning: Modulation of transmitter release. Science 218: 433-443.

Kemenes, G., K. Staras, and P.R. Benjamin. 1997. In vitro appetitive classical conditioning of the feeding response in the pond snail Lymnaea stagnalis. J. Neurophysiol. 78: $2351-2362$.

Kupfermann I. and K. Weiss. 1981. The role of serotonin in arousal of feeding behavior in Aplysia. In Serotonin neurotransmission and behavior (ed. B.L. Jacobs and A. Gelperin), pp. 255-288. MIT Press, Cambridge, MA.

Mackey, S.L., E.R. Kandel, and R.D. Hawkins. 1989. Identified serotonergic neurons LCB1 and RCB1 in the cerebral ganglia of Aplysia produce presynaptic facilitation of siphon sensory neurons. J. Neurosci. 9: 4227-4235.

Malyshev, A., N. Bravarenko, and P. Balaban. 1997. Dependence of synaptic facilitation postsynaptically induced in snail neurons on season and serotonin level. NeuroReport 8: 1179-1182.

Marchand, C.R., B. Griffond, K. Mounzih, and C. Colard. 1991. Distribution of methionine-enkephalin-like and FMRF-amide-like immunoreactivities in the central nervous system (including dorsal bodies) of the snail Helix aspersa Muller. Zool. Sci. 8: 905-913.

Maximova, O.A. and P.M. Balaban. 1984. Neuronal correlates of aversive learning in command neurons for withdrawal behavior of Helix lucorum L. Brain Res. 292: 139-149.

Smit, A.B., C.R. Jimenez, R.W. Dirks, R.P. Croll, and W.P. Geraerts. 1992. Characterization of a cDNA clone encoding multiple copies of the neuropeptide APGWamide in the mollusk Lymnaea stagnalis. J. Neurosci. 12: 1709-1715.

Vehovzsky, A., G. Kemenes, and K.S.-Rozsa. 1989. Monosynaptic connections between serotonin-containing neurons labeled by 5,6-dihydroxytryptamine-induced pigmentation in the snail Helix pomatia L. Brain Res. 484: 404-407.

Vehovzsky, A., L. Hernadi, K. Elekes, and P. Balaban. 1993. Serotonergic input on identified command neurons in Helix. Acta Biol. Hung. 44: 97-101.
Zakharov, I.S. and P.M. Balaban. 1987. Serotonin and aversive conditioning in adult and juvenile snails. In Cellular mechanisms of conditioning and behavioral plasticity (ed. C.Woody, D. Alkon, and J. McGaugh), pp.105-108. Plenum, New York, NY.

1991. Serotonergic modulation of withdrawal behavior in Helix. In Simpler nervous systems (ed. D.A. Sakharov and W. Winlow), pp. 316-329. Manchester University Press, Manchester, NY.

Zakharov, I.S., V.N. lerusalimsky, and P.M. Balaban. 1995. Pedal serotonergic neurons modulate the synaptic input of withdrawal interneurons in Helix. Invert. Neurosci. 1: 41-51.

Received January 26, 1999; accepted in revised form March 4, 1999.

$$
\begin{array}{lllllllllllllll} 
& E & A & R & N & I & N & G & \mathbf{8} \\
\mathbf{1 7 6} & M & E & M & O & R & Y
\end{array}
$$




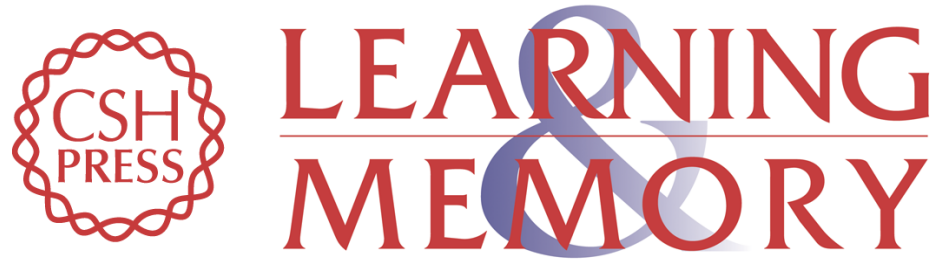

\section{Two Modulatory Inputs Exert Reciprocal Reinforcing Effects on Synaptic Input of Premotor Interneurons for Withdrawal in Terrestrial Snails}

Olga A. Maksimova, Natalia I. Bravarenko and Pavel M. Balaban

Learn. Mem. 1999, 6:

Access the most recent version at doi:10.1101//m.6.2.168

References This article cites 28 articles, 7 of which can be accessed free at: http://learnmem.cshlp.org/content/6/2/168.full.html\#ref-list-1

License

Email Alerting

Receive free email alerts when new articles cite this article - sign up in the box at the Service top right corner of the article or click here. 